\section{Commentary: Advanced imaging technologies may help to eliminate the need for pacemaker implantation following repair of ventricular septal defect}

\author{
Thierry Carrel, MD
}

Iatrogenic heart block remains a risk factor for surgical closure of ventricular septal defects (VSDs), with a reported incidence between $2 \%$ and $8 \%$. In a single-center, retrospective study with more than 800 patients (mean age, 14 months) undergoing operation between 2001 and 2009, a total of 64 patients $(7.7 \%)$ developed iatrogenic atrioventricular block. Forty-eight of them $(75 \%)$ had transient atrioventricular block, whereas $16(1.9 \%)$ required pacemaker implantation. ${ }^{1}$ Patients weighing $<4 \mathrm{~kg}$ and those with inlet VSD were more likely to develop atrioventricular block following surgical VSD repair. In another recent study by Sen and colleagues ${ }^{2}$ that included 286 patients, the type of suturing technique (interrupted vs continuous) had no significant influence on perioperative mortality and morbidity such as complete atrioventricular block $(6.8 \%$ vs $5.2 \%)$.

Yoshitake and colleagues ${ }^{3}$ performed a nice (postmortem) analysis of 8 hearts from pediatric patients with a perimembranous VSD. They used a combination of imaging (radiograph phase-contrast computed tomography) with 3-dimensional reconstruction software to provide the best possible analysis of the course and location of the atrioventricular conduction system. Similar anatomical analyses were performed decades ago and therefore the present study mainly confirms the available knowledge. Among the main advantages of this technology is that Amira software (ThermoFisher Scientfic,

\footnotetext{
From the Department for Cardiovascular Surgery, University Hospital and University of Bern, Bern, Switzerland.

Disclosures: Author has nothing to disclose with regard to commercial support. Received for publication March 8, 2020; revisions received March 8, 2020; accepted for publication March 9, 2020; available ahead of print March 25, 2020. Address for reprints: Thierry Carrel, MD, Department for Cardiovascular Surgery, University Hospital, CH-3010 Bern, Switzerland (E-mail: thierry.carrel@insel.ch). J Thorac Cardiovasc Surg 2020;160:497-8 0022-5223/\$36.00

Copyright () 2020 by The American Association for Thoracic Surgery https://doi.org/10.1016/j.jtcvs.2020.03.047
}

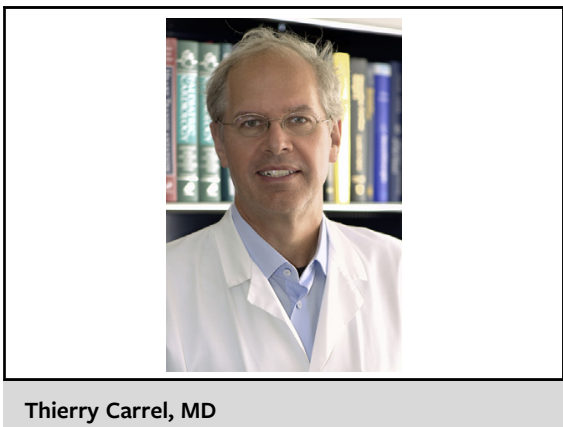

CENTRAL MESSAGE

New imaging and 3D reconstructive technologies may help to avoid pacemaker implantation following repair of complex congenital malformations associated with ventricular septal defect.

Waltham, Mass) reconstruction made it possible to get a view similar to that of a surgeon in an operating room through reorientation of the dataset and to provide different views of the most vulnerable parts of the suture line.

Although the occurence of complete atrioventricular block following VSD repair is low, major interest may be focused on more complex intracardiac pathologies associated with VSD like tetralogy of Fallot, transposition, or double-outlet right ventricle. This is also true for patients with congenitally corrected transposition where uncertainty remains regarding the location of the conduction axis when this combination is found in the setting of mirror-imaged atrial arrangement.

The described method is appealing but it will need maximal attention by surgical teams to translate the exact location of the atrioventricular conduction bundle as well as the atrioventricular node into the surgical anatomy at the time of VSD closure, although longitudinal-not perpendicular-sutures are placed at the level of the inferoposterior rim of the defect.

It would be extremely useful to have precise knowledge of the location of the bundle as part of the preoperative assessment to prevent the rare but significant complication of postoperative heart block. Among the most important limitations is the fact that the authors cannot confirm that this type of imaging analysis may be applied to living 
hearts. Computed imaging technologies will get better, as every technology does.

\section{References}

1. Siehr SL, Hanley FL, Reddy VM, Miyake CY, Dubin AM. Incidence and risk factors of complete atrioventricular block after operative ventricular septal defect repair. Congenit Heart Dis. 2014:9:211-5.
2. Sen O, Kadirogullari E, Aydin U, Guler S, Haydin S. Comparison of continuous and interrupted suturing techniques in ventricular septal defect closure. Heart Surg Forum. 2018;21:E418-22.

3. Yoshitake S, Kaneko Y, Morita K, Hoshino S, Oshima Y, Masashi T, et al. Visualization and quantification of the atrioventricular conduction axis in hearts with ventricular septal defect using phase contrast computed tomography using phase-contrast computed tomography. J Thorac Cardiovasc Surg. 2020;160: 490-6.
See Article page 490.

\section{Commentary: Validation of our understanding of atrioventricular conduction anatomy using phase-contrast computed tomography}

\author{
Bahaaldin Alsoufi, MD
}

The anatomy of the atrioventricular conduction system in relation to ventricular septal defects (VSDs) has been demonstrated histologically since the early 1960s. ${ }^{1,2}$ Subsequently, surgeons adopted strategies to close VSDs while avoiding atrioventricular conduction and that has resulted in a remarkable decrease in the incidence of complete heart block following surgical repair of VSDs. ${ }^{3,4}$ In the account following up the early pioneering work of Lillehei repairing congenital heart defects, 4 of 27 patients in whom defect closure was attempted developed complete heart block. ${ }^{5}$ Subsequent to the surgical modifications in suturing techniques, the incidence of complete heart block following surgical closure of VSDs has substantially decreased, with the current expected risk being less than $1 \%$ to $2 \%$. ${ }^{3,4}$

Phase-contrast computed tomography (PCCT) is an advanced imaging technology that allows visualization of

From the Department of Cardiovascular and Thoracic Surgery, University of Louisville School of Medicine, Norton Children's Hospital, Louisville, Ky.

Disclosures: Author has nothing to disclose with regard to commercial support.

Received for publication March 9, 2020; revisions received March 9, 2020; accepted for publication March 9, 2020; available ahead of print April 5, 2020.

Address for reprints: Bahaaldin Alsoufi, MD, Department of Cardiovascular and Thoracic Surgery, University of Louisville School of Medicine, Norton Children's Hospital, 201 Abraham Flexner Way, Suite 1200, Louisville, KY 40202 (E-mail: balsoufi@hotmail.com).

J Thorac Cardiovasc Surg 2020;160:498-9

$0022-5223 / \$ 36.00$

Copyright (c) 2020 by The American Association for Thoracic Surgery

https://doi.org/10.1016/j.jtcvs.2020.03.052
Check for updates

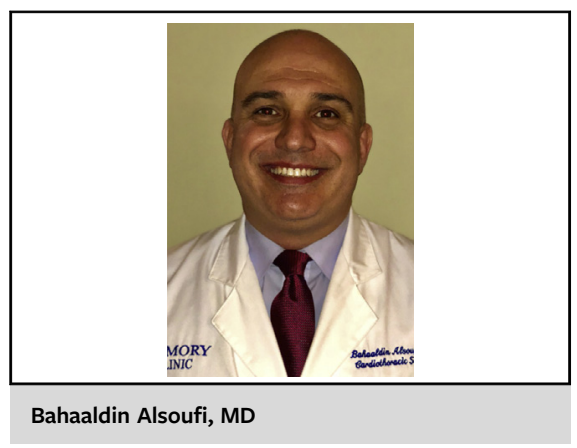

CENTRAL MESSAGE

Phase-contrast computed tomography validates our existing

knowledge of atrioventricular

conduction relationship to ven-

tricular septal defects based on

previous histologic studies.

fine-density distribution that regularly represents key structural information in soft tissues with 1000 times greater resolution and considerably greater contrast than conventional computed tomography. ${ }^{6}$ Using PCCT technology, recent studies have demonstrated the feasibility of 3-dimensional visualization of the atrioventricular conduction axis in normal human hearts. ${ }^{6,7}$ In the current issue of the Journal, Yoshitake and colleagues ${ }^{8}$ examined hearts from 8 deceased children known to have unrepaired VSDs. They imaged these hearts using PCCT available at the SPring-8 synchrotron radiation facility in Hyogo, Japan. They were able to identify the atrioventricular conduction system in 7 of 8 specimens and were able to describe precisely the relationship between the conduction system, VSDs, and ventricular septum. In essence, they provided outstanding 3-dimensional images that validated our existing knowledge of conduction system anatomy based on the previous histologic studies and assured that the current suturing techniques 